Vol. 1, No. 3, 2019

Jurnal Terapan Sains \& Teknologi

Fakultas Sains dan Teknologi - Universitas Kanjuruhan Malang

\title{
PERBANDINGAN ANTARA CERTAINTY FACTOR DAN FORWARD CHAINING UNTUK MENENTUKAN PENYAKIT KOLESTEROL BERBASIS ANDROID
}

\author{
Adyatna Sih Mahfudha ${ }^{1}$, Syahminan ${ }^{2}$ \\ Program Studi Teknik Informatika, Universitas Kanjuruhan ${ }^{1,2,3}$ \\ Adyatna199@gmail.com ${ }^{1}$, Syahminan@unikama.ac.id ${ }^{2}$
}

\begin{abstract}
Abstrak. Analisa perbandingan dua metode yang digunakan untuk menyelesaikan suatu kasus permasalahan antara lain merupakan Certainty Factor dan Forward Chaining. Certainty factor dapat gunakan dalam nilai guna memperkirakan derajat kepercayaan seorang ahlidalam menilai suatu data. Metode ini sangat cocok dalam sistem sebagai tolak suatu apabila memiliki kepastia dan tidak kepasstani guna menganalisa penyakit. Sedangkan forwour Chaining merupakan metode pencarian atau teknik pelacakan ke depan yang dimulai dengan informasi yang ada dan memadukan dalam bentuk rule untuk menghasilkan suatu kesimpulan atau tujuan. Salah satu penerapan perbandingan 2 metode ini adalah untuk menentukan penyakit kolestrol berbasis android. Maka dari itu dibuat suatu perbandingan metode certianty factor dan forward chaining Untuk Menentukan Penyakit Kolestrol Berbasis Android. Program di terapkan di dalam handphone.
\end{abstract}

Kata Kunci: certianty factor, forward chaining, kolesterol, android.

\section{PENDAHULUAN}

Perkembangan teknologi saat ini mengalami perkembangan yang begitu maju diantaranya dibidang telekomunikasi telepon seluler sebagai media menghubungkan satu sama lainnya berbagai software di tanamkan di dalam aplikasi tersebut salah satunya adalah alat menghitung/kalkulator, aplikasi rumus, aplikasi permainan dan banyak aplikasi unutk telepon celuler..keterbaruan Aplikasi seluler dengan mempergunakan sistem software javaandroid.

Analisa perbandingan dua metode yang digunakan untuk menyelesaikan suatu kasus permasalahan antara lain merupakan Certainty Factor dan Forward Chaining. Implementasi dari penggunaan metode certainty factor digunakan dalam bidang kesehatan karena sistem dipandang sebagai cara penyimpanan pengetahuan pada bidang tertentu dalam pemograman komputer sampai penentuan putusan untuk memberikan kedalam suatu penalaran secara pintar. Melalui Faktor Kepastian (Certainty factor) ialah merupakan pernyatan dalam bentuk terejadinya (fakta atau hipotesis) berdasarkan fakta atau nilai pakar. Certainty factor mempergunakan suatu nilai ukur untuk mengasumsikan nilai derajat pastian pakar pada suatu data. Metode CF sanagt tepat sebagai sistem untuk mengukur suatu kepastian atau tidak pastian dalam menganalisasuatu penyakit. Sedangkan Metode Forward Chaining merupakan suatu cara untuk mencari dan untuk menentukan sauutu pencarian solusi untuk memecahkan masalah dimana fungsi dari perhitungan metode tersebut mengantikan dapat mengantikan fungsi pakar dengan mengunakan aplikasi berbasis suatu aplikasi dengan menggunakan salah satu metode yaitu forwor chaining dengan menerapkan perbandingan kedua metode ini sebbagai solusi permasalahan menentukan suatu penyakit dapat teratasi. Salah satu penerapan perbandingan metode ini adalah untuk menentukan penyakit kolestrol berbasis android.

Mengingat keterbatasan waktu pengerjaan yang ada maka penulis membatasi permasalahan sebagai berikut :

1. Dengan penggunaan aplikasi sistem pendukung keputusan ini hanya menampikan gejala-gejala yang ditimbulkan oleh penyakit kolestrol serta cara penanganannya. 
2. Dengan menggunakan metode forward chaining dan teori certainty factor akan mendapatkan hasil berupa kepastian yang akan sesuai dengan data yang diisi oleh pasien penyakit kolesterol. Penggunaan aplikasi ini hanya menampilkan informasi jenis penyakit kolesterol tinggi pada umumnya seperti : iskemia sementara otak,iskemia jantung,dan iskemia mata.

3. Sistem dapat melakukan perbandingan metode untuk menentukan analisa terbaik berdasarkan studi kasus penulis.

Tujuan penelitian ini adalah: 1). Untuk mengetahui jenis penyakit kolesterol dengan menganalisa gejala - gejala yang tampak dengan menggunakan metode certainty factor dan forward chaining. 2).Untuk mengetahui tingkat perbandingan dari metode certainty factor dan forward chaining. Dimana output dari analisa metode certainty factor dan forward chaining untuk menentukan penyakit kolesterol.

\section{METODE PENELITIAN}

Kolesterol adalah lipid amfipatik ini penting mengenai aturan permeabilitas dan fluiditas membran, untuk sebagai lapisan luar lipoprotein plasma (Bothamdan Mayes, 2012). Kolesterol ialah sterol yang dikenali oleh sebagai manusia. Kolesterol memiliki pengartian yang lebih dari satu untuk itu bagian lainnya dipererlukan yang dapat membahayakan, bergantung berapa jumlah dapat terkandung dalam tubu manusia yang di bagian mana (Almatsier, 2010). Kolesterol merupakan satu struktur organik yang mempunyai berat molekul 386 Da dan memiliki 27 atom karbon, dengan nilai 17 antaranya digolongkan dalam empat ring yang digabung, lebih dari satu dirmasuk pada satuan metil segi yang melekat pada pertemuan cincin $\mathrm{AB}$ dan $\mathrm{CD}$, dan delapan ialah pada rantai perifer. Kolesterol disusun oleh karbon hidrogen dan karbon, dan kelompok hidroksil soliter berlekatan pada C3. Kolesterol memiliki jenuh sebagai sempurna, diiliki dalam satuan ikatan ganda C5 dan C6 (Dominiczak dan Wallace, 2010). Kolesterol ialah komponen esensial membran struktural semua sel merupakan komponen utama sel otak dan saraf. Kolesterol terdapat pada konsentrasi tinggi pada jaringan kelenjar yang ada didalam hati kolesterol disintesis dan tersimpan.

\section{Jenis Kolesterol}

Menurut ( Lars Heslet,2011). Macam-macam jenis kolesterol yang harus di pahami

1. Kolesterol LDL (low density lipoprotein)

Kolesterol LDL merupakan kolesterol yang membawa paling banyak kolesterol banyak dapat menimbulkan terendapnya kolesterol pada arteri. Kolesterol LDL adalah faktor berbahaya penting penyakit jantung koroner yang merugikan

2. Kolesterol HDL (high density lipoprotein)

Kolesterol HDL membawa kolesterol sedikit. HDL seiring disebut kolesterol baik, dikarena didapatkan selalu mengurangi beban berlebiihan kolesterol tiadak baik dalam pembulu darah kembali ke hati guna memproses dibuang. Jadikan HDL guna mencegah kolesterol terendap pada anteri dan dilindungi (proteksi) dalam aterosklerosis (terbentuknya plak dan dinding pembulu darah). Selain LDL / HLD terdapat juga berbagai jenis lemak yang berbahaya, yakni trigliserida. Trigliserida adalah salah satu jenis lemak yang terdapat dalam darah dan berbagai organ dalam tubuh. Meningkatnya kadar trigliserida dalam darah dapat meningkatkan kadar kolesterol. Dengan jumlah faktor didapat terpengaruhi kadar trigliserida didalam darah anatarlain kegemukan, minum alkohol, makanan gula-gula, makanan lemak. Kadar trigliserida yang tinggi banyak dikaitkan dengan pankreatitis atau radang pankreas. 


\section{HASIL DAN PEMBAHASAN}

\section{Analisis}

Analisis sistem adalah penguraian dari suatu sistem informasi secara penuh didalam berbagai komponennya untuk maksud guna mengidentifikasi dan evaluasi rmasalah, , terbatan dan terjadi guna kebutuhan yang mengharapkan sehingga guna usulkan membaiki.

Berdasarkan latar belakang diatas, penyakit kolestrol di Indonesia didapatkan keadaan dimana kolesterol total $>240 \mathrm{mg} / \mathrm{dl}$ pada orang berusia di atas 55 tahun yaitu lebih dari $56 \%$. Berdasarkan dari hasil survey peneliti di 5 puskesmas di Kota Malang tahun 2016 didapatkan angka tertinggi pasien hiperkolesterolemia sebanyak 36 orang (dari bulan Januari-Oktober 2016). Kolesterol yang diproduksi oleh tubuh terdiri dari 2 jenis, yaitu kolesterol HDL (High Density Lipoprotein) yang biasa disebut dengan kolesterol baik dan kolesterol LDL (Low Density Lipoprotein) disebut dengan kolesterol jahat. Kolesterol LDL akan menumpuk pada dinding pembuluh darah arteri. Koroner yang menyebabkan penyumbatan, karena itu LDL disebut sebagai kolesterol jahat.

Tingginya penderita penyakit kolestrol ini dapat menyebabkan kematian,untuk menanggulangi masalah tersebut penulis mengambil judul penelitian Perbandingan antara Certainty Factor dan Forward Chaining untuk menentukan penyakit kolesterol berbasis android.

\section{A. Representasi Pengetahuan}

Representasi pengetahuan merupakan metode yang digunakan untuk mengodekan pengetahuan dalam sebuah sistem pakar berbasis pengetahuan. Bahasa representasi harus dapat membuat seorang pemrogram mampu mengekpresikan pengetahuan sehingga dapat diterjemahkan ke dalam bahasa pemrograman dan dapat disimpan agar mendapatkan solusi pemecahan.

Representasi pengetahuan diagnosa penyakit kolesterol dapat dilihat pada tabel 3.1 Tabel pengkodean penyakit kolesterol, Tabel 3.2 Pengkodean Gejala Penyakit kolesterol dan Nilai Persentasenya dan Tabel 3.3 Tabel Solusi

Tabel penyakit berfungsi untuk merepresentasikan pengetahuan tentang nama penyakit kedalam bentuk kode-kode.

Tabel 3.1 berikut ini merupakan tabel penyakit dari sistem yang akan dibangun.

Tabel 1. Pengkodean Penyakit Kolestrol

\begin{tabular}{ll}
\hline Kode & Penyakit Kolestrol \\
\hline P1 & Penyakit Jantung Koroner \\
\hline P2 & Penyakit Stroke \\
\hline P3 & Penyakit Hipertensi \\
\hline P4 & Penyakit Diabetes Melitus \\
\hline P5 & Penyakit Asam Urat \\
\hline
\end{tabular}

Tabel gejala berfungsi untuk merepresentasikan pengetahuan tentang gejala-gejala penyakit kedalam bentuk kode-kode. Tabel 3.2 berikut ini merupakan tabel gejala dari sistem yang akan dibangun.

Tabel 2. Pengkodean Gejala-Gejala Penyakit Kolesterol

\begin{tabular}{lll}
\hline Kode & Gejala-Gejala Penyakit Kolestrol & Bobot \\
\hline G1 & Dada terasa nyeri & 0,25 \\
\hline G2 & Pusing mendadak & 0,14 \\
\hline G3 & Mudah merasa lelah & 0,25 \\
\hline
\end{tabular}




\begin{tabular}{lll}
\hline G4 & Tiba-tiba mati rasa/lumpuh & 0,14 \\
\hline G5 & Gangguan penglihatan & 0,14 \\
\hline G6 & Sakit kepala & 0,17 \\
\hline G7 & Jantung berdebar-debar & 0,17 \\
\hline G8 & Nyeri sendi kaki & 0,14 \\
\hline G9 & Perasaan kaki terbakar & 0,14 \\
\hline G10 & Persendian bengkak & 0,14 \\
\hline G11 & Sering buang air kecil dalam jumlah banyak & 0,14 \\
\hline G13 & Sering kesemutan & 0,14 \\
\hline G14 & Sesak nafas & 0,25 \\
\hline G15 & Sakit kepala parah & 0,25 \\
\hline G16 & Pandangan mata kabur & 0,14 \\
\hline G17 & Jaringan mengeras pada sendi & 0,17 \\
\hline G18 & Kehilangan keseimbangan & 0,14 \\
\hline G19 & Mudah marah & 0,14 \\
\hline G20 & Sering kram & 0,17 \\
\hline G21 & Badan nyeri seperti tertusuk jarum & 0,14 \\
\hline G22 & Kebingungan mendadak & 0,14 \\
\hline G23 & Jempol kaki sakit & 0,14 \\
\hline G24 & Sulit berkosentrasi & 0,14 \\
\hline G25 & Sering merasa haus hebat & 0,17 \\
\hline G26 & Sendi terasa sangat gatal / bersisik & 0,14 \\
\hline G27 & Kulit terasa tebal & 0,14 \\
\hline G28 & Tidak bisa bergerak dengan bebas & 0,14 \\
\hline G29 & Sering merasa lelah dan lemas & 014 \\
\hline G30 & Kesulitan berbicara/bicara pelo & 0,14 \\
\hline G31 & Wajah menjadi kemerahan & 0,14 \\
\hline & & 0,17 \\
\hline
\end{tabular}

Tabel bobot certainty factor ini menjelaskan nilai bobot dari setiap kondisi.

Tabel 3. Tabel Bobot Certainty Factor

\begin{tabular}{ccc}
\hline No & Kondisi Tidak Pasti & CF \\
\hline 1 & Sangat Yakin & -1.0 \\
\hline 2 & Yakin & -0.8 \\
\hline 3 & Cukup Yakin & -0.7 \\
\hline 4 & Sedikit Yakin & -0.5 \\
\hline 5 & Tidak Yakin & 0.2 \\
\hline
\end{tabular}

\section{Aturan (Rule)}

Kaidah produksi biasanya dituliskan dalam bentuk IF-THEN, aturan mengakatakan memiliki kaitan implisit lebih dari satu bentuk adalah bagian premis (IF) yang lapisan konklusif (Then), bila dibagian premis terpenuhi, maka dibagian konklusi juga bernilai benar. Untuk 
masing-masing area gejala, terdapat juga aturan kaidah produksi gejala penyakit yang terhubung IF-THEN rules.

\section{Tabel 4. Tabel Aturan}

\begin{tabular}{cl}
\hline Penyakit & Aturan(Rules) \\
\hline P1 & $I F=\mathrm{G} 1, \mathrm{G} 13, \mathrm{G} 3, \mathrm{G} 14$ THEN P1 \\
\hline P2 & $I F=\mathrm{G} 4, \mathrm{G} 22, \mathrm{G} 30, \mathrm{G} 5, \mathrm{G} 15, \mathrm{G} 18, \mathrm{G} 2$ THEN P2 \\
\hline P3 & $I F=\mathrm{G} 6, \mathrm{G} 31, \mathrm{G} 7, \mathrm{G} 16, \mathrm{G} 24, \mathrm{G} 19$ THEN P3 \\
\hline P4 & $I F=\mathrm{G} 11, \mathrm{G} 25, \mathrm{G} 29, \mathrm{G} 12, \mathrm{G} 27, \mathrm{G} 21, \mathrm{G} 20$ THEN P4 \\
\hline P5 & $I F=\mathrm{G} 8, \mathrm{G} 23, \mathrm{G} 9, \mathrm{G} 17, \mathrm{G} 10, \mathrm{G} 26, \mathrm{G} 28$ THEN P5 \\
\hline
\end{tabular}

\section{B. Pengujian}

Pada tahap ini merupakan proses dilakukan pembuatan kode program sesuai dengan hasil tahapan desain sistem. Tahapan pemrograman mengimplementasikan hasil penerjemahan design dalam bahasa yang bisa dikenali oleh mesin atau komputer.

Activity halaman utama ini adalah tampilan awal program saat pertama kali dijalankan. Halaman utama ini terdiri dari logo universitas, judul sistem nama mahasiswa dan nim mahasiswa.

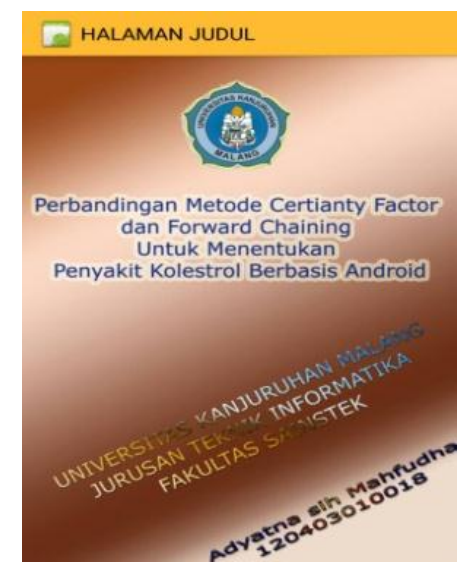

\section{Gambar 1 Activity Halaman Utama/judul}

\section{Implementasi Activity Halaman Home}

Activity halaman home ini menampilkan menu-menu pada sistem

yang terdiri dari menu home, menu profil, menu database, menu analisa, menu info CF, menu info FC, menu info dan menu keluar.

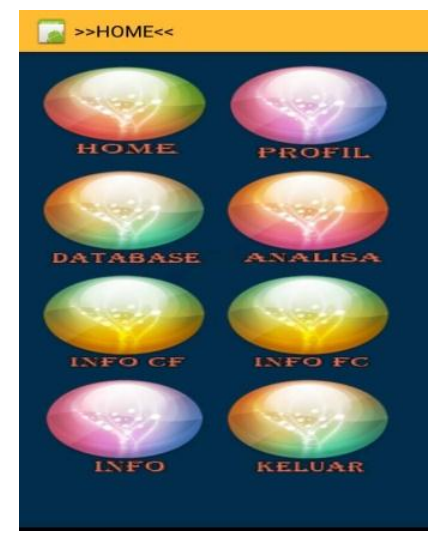

Gambar 2. Activity Halaman Home 


\section{Implementasi Activity Halaman Profil}

Activity halaman profil ini adalah profil biodata mahasiswa. Profil biodata ini terdiri dari nama mahasiswa, nim mahasiswa, jurusan mahasiswa, fakultas mahasiswa, tahun ajaran, no telepon mahasiswa dan email mahasiswa.

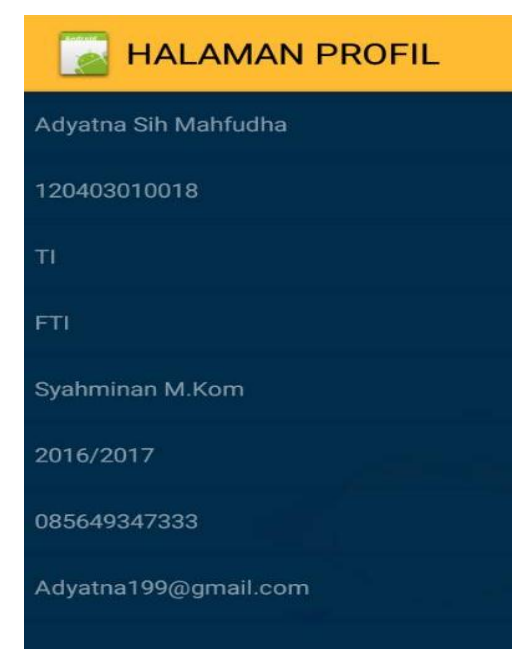

Gambar 3. Activity Halaman Profil

\section{Implementasi Activity Halaman Analisa}

Halaman analisa ini adalah halaman yang menampilkan data-data gejala penyakit kolestrol yang harus dipilih oleh user untuk menganilsa penyakit. User memilih dengan pilihan jawaban sangat yakin, yakin, cukup yakin, sedikit yakin dan tidak.

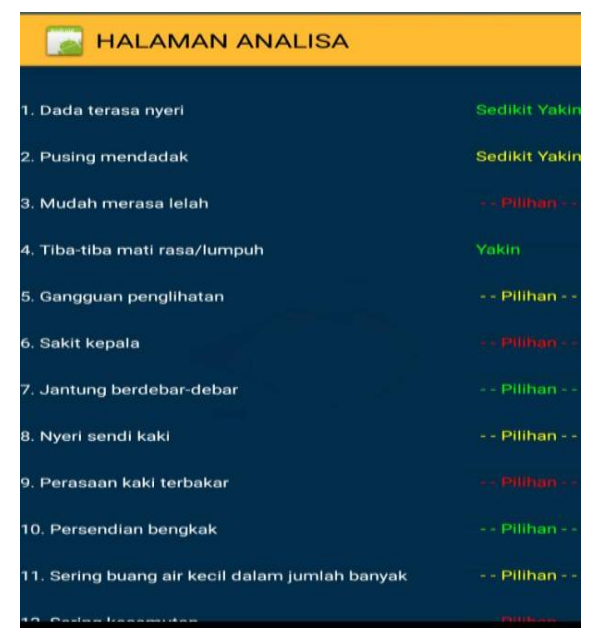

Gambar 4. Activity Halaman Analisa

\section{Implementasi Activity Halaman Hasil Perhitungan Certainty Factor}

Halaman hasil perhitungan CF ini menampilkan dari hasil dari data analisa user.

\section{Implementasi Activity Halaman Hasil Perhitungan Forward Chaining}

Halaman hasil perhitungan FC ini menampilkan dari hasil dari data analisa user. 

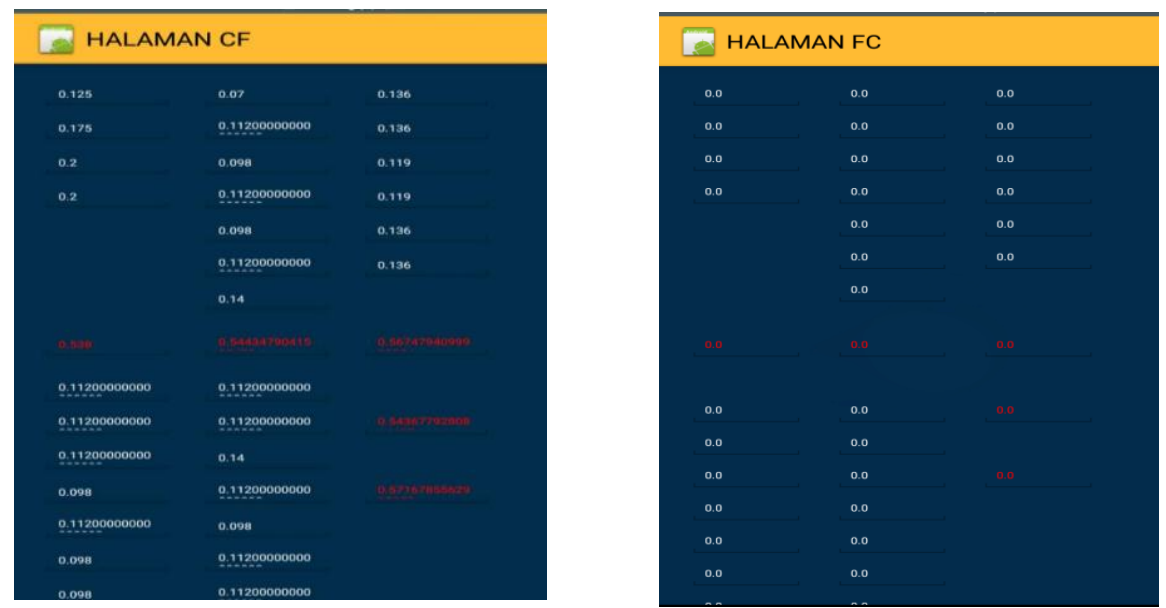

Gambar 5. Activity Halaman Hasil Perhitungan Certainty Factor Activity Halaman Hasil Perhitungan Forward Chaining

\section{Implementasi}

Pada tahap implementasi dilakukan pemeliharaan sistem secara berkala, evaluasi sistem agar sistem dapat tetap berjalan dan berkembang sesuai dengan kebutuhan dan fungsinya.

\section{PENUTUP}

Setelah melakukan perancangan, pengujian, dan analisis, maka dapat diperoleh kesimpulan sebagai berikut:

1. Telah berhasil dibuat aplikasi sistem pendukung keputusan berbasis android untuk mendeteksi dan menangani penyakit kolesterol.

2. Merancang sistem pendukung keputusan pendeteksi penyakit kolesterol menggunakan metode certainty factor dan forward chaining.

\section{DAFTAR PUSTAKA}

Abubakar, M.A., Kowalski, S.R. (2010). A Comparative analysis of the Libyan national essential medicines list and the WHO model list of essential medicines.

Ardhila City, Oktaviani noni, (2003). Diaskol Jantroke (Diabetes melitus, asam urat, Kolesterol, jantung dan Stroke).IN azna Book, Yogyakarta. hal 30-35

Laurentia, YS, 2012. Deslipidemia pada Obesitas dan Tidak Obesitas. Semarang: Fakultas Kedokteran Universitas Diponegoro.

Peter A. mayes, 2003, Biokimia harper, alih bahasa Andry Hartono, Edisi5, Jakarta.

S. J. Russell dan P. Norvig, Artificial Intelligence: A Modern Approach, 2nd penyunt., United States of America: Prentice Hall, 2003. 